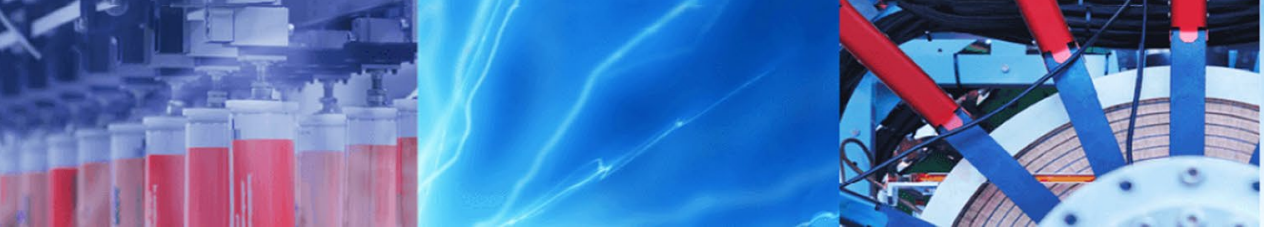

Research Article

\title{
Spatial and time resolved determination of the vibrational temperature in ignition sparks by variation of the dwell time
}

\author{
Tobias Michler $^{1}$ (D) . Olaf Toedter ${ }^{1} \cdot$ Thomas Koch $^{1}$
}

Received: 30 March 2020 / Accepted: 17 June 2020 / Published online: 30 June 2020

(c) The Author(s) 2020 OPEN

\begin{abstract}
The ignition process initiates the combustion in spark-ignition engines. Therefore, understanding the ignition process is an important aspect in developing more efficient combustion engines. In this thesis, the vibrational temperature of an ignition spark in air under atmospheric pressure and room temperature is observed in spatial and temporal resolution. The temperature is determined by comparing simulated spectra with the measured spectra of the second positive system of $\mathrm{N}_{2}$ between 360 and $381 \mathrm{~nm}$. Changing the dwell time had no significant effect on the vibrational temperature of the three spark phases. In the breakdown the vibrational temperature is about $3300 \mathrm{~K}$. The vibrational temperature of the following arc discharge is in the range of $3750 \mathrm{~K}$ to $4350 \mathrm{~K}$. The glow discharge is divided into the negative glow and the positive column. Both show similar vibration temperatures in the range of $3500 \mathrm{~K}$ to $3900 \mathrm{~K}$.
\end{abstract}

Keywords Ignition system · Vibrational temperature · Dwell time · Breakdown · Arc discharge · Glow discharge

\section{Introduction}

The climate target of the European Union (EU) for 2030 is a $40 \%$ reduction of greenhouse gases compared to 1990 and an increase in energy efficiency of $32.5 \%$ [1]. Furthermore, the long-term strategy is a climate-neutral EU in 2050 [2]. Kramer et al. [3] shows, that by 2030 vehicles with internal combustion engines will still be the majority. In order to achieve the climate targets nevertheless, fuels from renewable sources will make an important contribution, as several life cycle analyses and studies show [4-6]. Since the production of these fuels is also linked to high energy requirements [7], it is important to further optimize combustion engines to make them more energy efficient.

Diluted or lean mixtures can improve the efficiency and reduce the pollutant emissions [8-10] such as $\mathrm{NO}_{\mathrm{x}}$ of internal combustion engines. In order to ignite these mixtures, a higher energy input from the ignition spark is required [11-13]. Besides the higher inflammation probability, this can also lead to increases spark plug wear. Furthermore, the flame speed decreases with diluted and lean mixtures and the cyclic-fluctuations increase [14, 15], which reduces the efficiency of the engine. This can be counteracted with higher flow velocities. These contribute to the support of flame propagation, but also lead to higher cyclical-fluctuations due to quenching effects on the flame kernel. Furthermore, these cyclic-fluctuations can also be caused by unfavorable mixture conditions at the spark plug [16]. As an alternative to the improved flow, pre-chamber spark plugs can increase the flame velocity due to their high penetration depth of the torch jets by igniting more mixture volumetrically $[17,18]$. Due to the potential problems of pre-chamber flushing, the compatibility of the ignition system with regard to exhaust gas recirculation (EGR) [19] must be high. Because of the compromise between inflammation probability and spark plug wear, the ignition process and the physic of the ignition spark must be further observed. In particular, the effect of

Tobias Michler, tobias.michler@kit.edu; Olaf Toedter, olaf.toedter@kit.edu | ${ }^{1}$ Karlsruhe Institute of Technology, Kaiserstraße 10, 76131 Karlsruhe, Germany. 
the different spark phases and their influence and ignition must be investigated.

In 1977 Rudolph Maly described for the first time the ignition spark in its three discharge phases breakdown, arc and glow discharge [20]. He also described the physical mechanism and properties behind these discharges in detail in further publications [21-23]. Due to the high currents in the breakdown, which he estimated according to Ohm's law, he assumed a temperature of $60,000 \mathrm{~K}$ for this discharge. By using arcs with high current of $10 \mathrm{~A}$, he determined a temperature of $5000 \mathrm{~K}$ to $6000 \mathrm{~K}$, which only varied slightly with the arc current. For the glow discharge Maly determined about $3000 \mathrm{~K}$ under steady-state conditions. Later spectroscopic observations by Oliveira et al. [24] measured, under atmospheric pressure using the second positive system (SPS) of $\mathrm{N}_{2}$ (C-B), gas temperatures between $1600 \mathrm{~K}$ and $2800 \mathrm{~K}$, and electron temperatures between $17,000 \mathrm{~K}$ and $20,000 \mathrm{~K}$. In comparison, Hnatiuc et al. [25] used the $\mathrm{OH}(\mathrm{A}-\mathrm{X})$ band at $306 \mathrm{~nm}$ to estimate rotational temperature, and the SPS of $\mathrm{N}_{2}$ for vibrational temperature. Hnatiuc assumed the electron temperature is higher than $10,000 \mathrm{~K}$ due to the reduced electric field. Time resolved temperature measurements with variation of the ignition system were performed by Huang et al. [26]. They calculated the rotational and vibrational temperature of the ignition spark to be $1400 \mathrm{~K}$ to $2600 \mathrm{~K}$ and $3700 \mathrm{~K}$ to $4300 \mathrm{~K}$, respectively, observing the $\mathrm{N}_{2}$ SPS.

In this work, the vibrational temperature is determined in high spatial and temporal resolution with the SPS of $\mathrm{N}_{2}$. The vibrational-exciting molecules serve as energy stores, which can make the plasma more reactive $[27,28]$. Therefore, the vibrational temperature is an important parameter for understanding the inflammation behavior of the three different spark phases. These resolutions allow the vibrational temperature determination of the different discharge phases and their characteristic plasma structure. This resolution of the plasma structure is particularly necessary in the case of glow discharge and the breakdown. In the different areas of the glow discharge different electron supply mechanisms and acceleration mechanisms can be observed, which could have an influence on the different plasma temperatures. In addition, the plasma temperatures can vary over the spark gap during the breakdown through the forming of streamers. The experiments were performed in an air atmosphere at a pressure of one bar and a temperature of $23^{\circ} \mathrm{C}$. Thus, the applied method shall be evaluated for later experiments under higher pressures in a heated pressure chamber. The aim of this investigations is to evaluate the influence of the dwell time on the vibrational temperature. The overall aim is to find out the different plasma properties of the ignition spark and their influence on the inflammation process in spark-ignition engines ( $\mathrm{SI}$ engines). This contributes to increasing the efficiency of SI engines.

This work is divided into five sections. In Sect. 2 and the underlying first three subsections, the ignition system as well as the electrical and the spectroscopic measurement setup are explained. In the second half of this section, first the calculation of the electrical energy and the methodology for excitation and determining vibrational temperature are explained. The last sub-section of Sect. 2 contains the measurement uncertainty in the determination of the vibrational temperature. Sect. 3 shows the results of the electrical energy and the vibrational temperature of the three spark phases breakdown, arc discharge and glow discharge each in a sub-section. The penultimate Sect. 4 the results are discussed, with the emphasis on the influence of the dwell time. In the last Sect. 5 a short conclusion is given.

\section{Measurement setup and methodology}

The following section contains information about the measurement setup and the methodology used.

\subsection{Measurement setup}

This section provides an overview of the measuring instruments used. First, the electric circuit of the used ignition system is explained, followed by the presentation of the electrical measurement setup. The third part contains the spectroscopic measurement setup. In the last section, the trigger chain for generating the time-resolved measurements is explained.

\subsubsection{Ignition system}

The electric parameters of the ignition system contain the energy sources of the ignition spark. Figure 1 shows the electric circuit of the ignition system used. Due to the location and type of the energy stores in the circuit, their associated time constants differ. Therefore, these energy stores release their energy in different time intervals, which fed the different spark phases. For example, the only system parameter, that can be completely discharged during the short breakdown phase of approximately $10 \mathrm{~ns}$ [29], is the capacitor $\mathrm{C}_{\mathrm{SP} 2}$, which is located in the spark plug below the suppression resistor $\mathrm{R}_{\mathrm{Sp}}$. For this reason, in earlier work [30] the division into the four spark phases breakdown, capacitive arc phase, inductive arc phase and glow discharge was chosen. This convention is based to the original subdivision of the three phases breakdown, (instationary) arc phase and glow phase described by Maly [20-23]. 
Fig. 1 Electric circuit of the ignition system used. The spark plug includes two capacitors with different time constants. (inspired by [31])

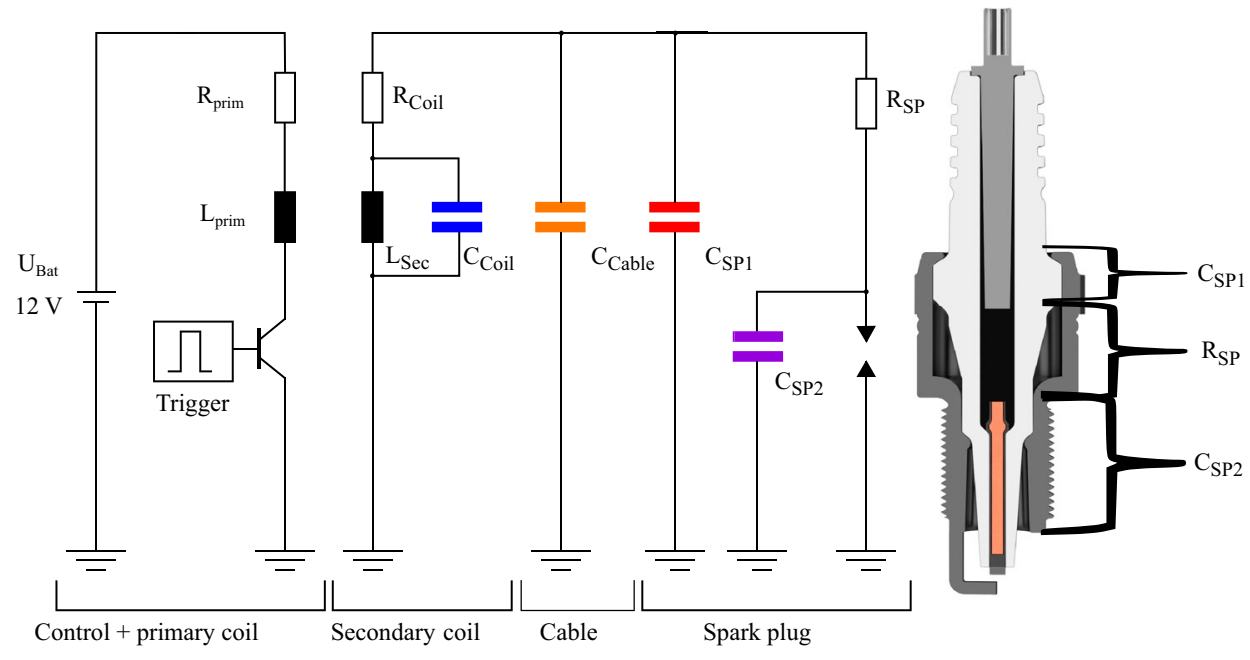

In this work, a common cassette coil is used. The charging time of the primary circuit (dwell time) is given by the length of the trigger signal. The ignition coil provides an initial spark current of $150 \mathrm{~mA}$ and an energy of $90 \mathrm{~mJ}$ at maximum dwell time of $3.3 \mathrm{~ms}$. The power supply is a $12 \mathrm{~V}$ car battery.

A spark plug with a nickel electrode is used. The electrode gap is $0.9 \mathrm{~mm}$ with a diameter of the center electrode of $2.5 \mathrm{~mm}$. The value of the suppression resistor $R_{S P}$ is $6.5 \mathrm{k} \Omega$. The capacitance of the capacitors $C_{\mathrm{SP} 1}+C_{\mathrm{SP} 2}$ is $12.5 \mathrm{pF}$ and was measured with a HAMEG LCR METER $\mathrm{HM} 8018$. Considering the geometry of the spark plug, the capacitance of the capacitor $C_{S P 2}$ is $8.33 \mathrm{pF}$. With the same measurement instrument the inductance of the spark plug of $530 \mu \mathrm{H}$ was measured. This inductance is negligible compared to the inductance of $10^{1} \mathrm{H}$ of the coil [32]. The capacitance of the cable is also negligible.

\subsubsection{Electric measurement setup}

A Tektronix P6015A is used to measure the high voltage. This is connected to the ignition coil and the spark plug via two ignition cables. The high-voltage probe has a cut-off frequency of $75 \mathrm{MHz}$. With the connected $3 \mathrm{~m}$ cable of the corresponding compensation box, the rise time is $4.67 \mathrm{~ns}$.

A Pearson 2877 current monitor is used for current measurement. The lower cut-off-frequency is $300 \mathrm{~Hz}$, the upper $200 \mathrm{MHz}$. Its rise time is $2 \mathrm{~ns}$. Two current clamps are installed to measure the current from the spark plug capacitors. One in front of the spark plug on the high-voltage probe and the other on the ground path of the system.

The data are recorded by a LeCroy Waverunner 6030A oscilloscope with a bandwidth of $350 \mathrm{MHz}$. The input resistance is $1 \mathrm{M} \Omega$ with an input capacitance of $20 \mathrm{pF}$. Both, the high-voltage probe and the current clamps are connected with an input coupling of $1 \mathrm{M} \Omega$. Due to the large amount of data and the storage speed of the oscilloscope, a sampling rate of $10 \mathrm{MS} / \mathrm{s}$ is chosen. Figure 2 shows the arrangement of the overall system.

\subsubsection{Spectroscopic measurement setup}

To collect the light from the plasma, a Hamamatsu A4869 lens is used. The lens has a transmission coefficient above $70 \%$ in the measured wavelength range of $300 \mathrm{~nm}$ to $800 \mathrm{~nm}$. The light is directly guided to the entrance slit of the spectrograph, which width is set to $200 \mu \mathrm{m}$. The spectrograph is an Acton SP2556 from Princeton Instruments with a focal length of $500 \mathrm{~mm}$. In this work the spectrograph uses a 600 grooves $/ \mathrm{mm}$ grating.

The spectra are recorded by a PI-MAX 2 intensified charge-couple device camera (iCCD camera) from Princeton Instruments. The full-size resolution of the CCD is $1024 \times 256$ pixels. In this case, the ignition spark uses 74 pixels in height. With the grating used, the detector coverage in the wavelength direction is $85 \mathrm{~nm}$. Therefore, a maximum resolution of $0.08 \mathrm{~nm} / \mathrm{pixel}$ is possible. The instrumental broadening function is $4.9 \AA$ (which is the full width at half maximum, FWHM), measured with a LOTOriel LSP035 mercury-argon lamp.

The Winspec software is used to operate the spectrograph. Winspec is also used for the main control of the trigger chain, which is explained in the following subsection. All operation settings are made by the software. For all measurements the gain is set to 255 , which is the maximum possible gain. The gate duration is not constant and depends on the point in time of the ignition spark.

\subsubsection{Trigger chain}

The initial trigger signal originates from Winspec. The initial trigger pulse is transmitted to the programmable 
Fig. 2 Schematic of the electric and spectroscopic setup

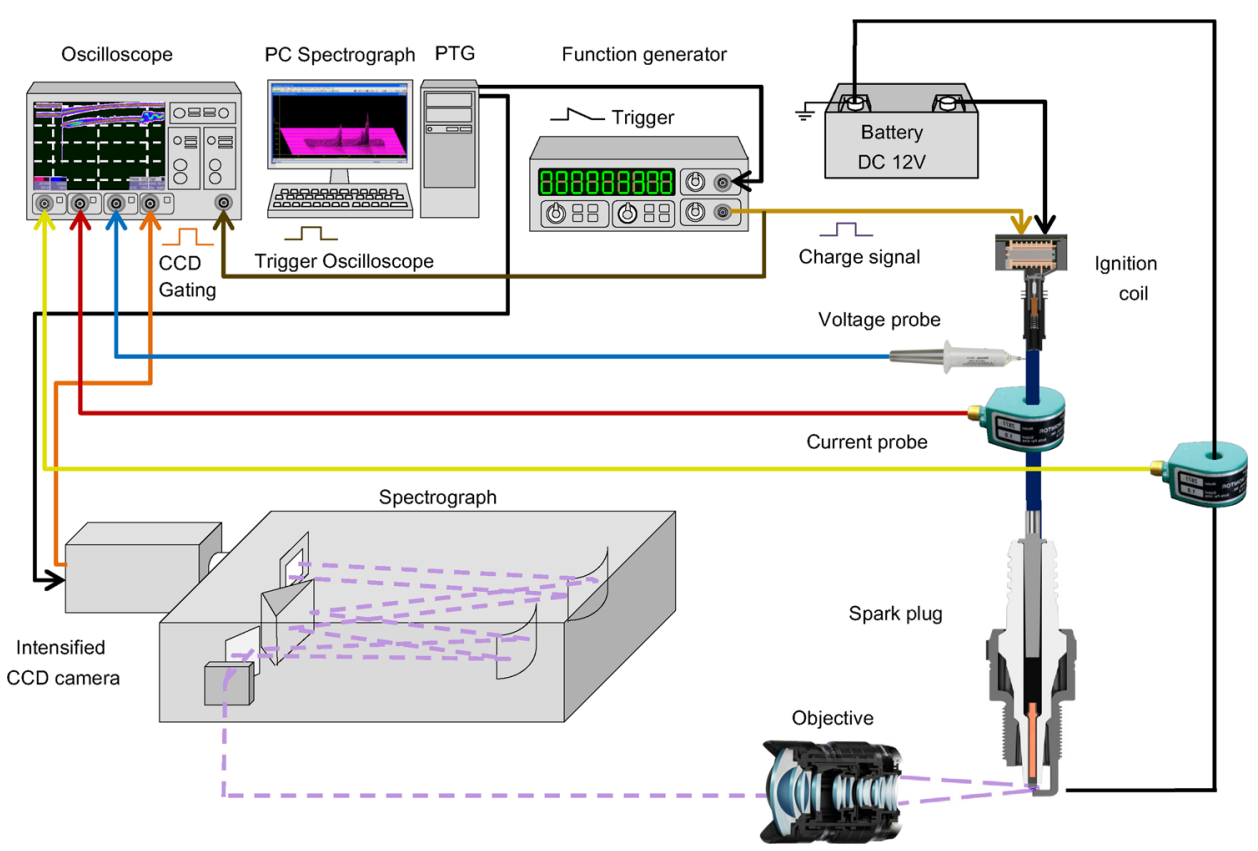

timing generator (PTG). First, the PTG sends the charging signal to the Hameg HM8139 function generator, which transmits a transistor-transistor logic signal (TTL signal) with the length of the dwell time to the ignition coil. This charging signal is also used as trigger signal for the oscilloscope.

A second time-delayed trigger signal is sent from the PTG to the iCCD camera. This delay is set by Winspec and depends on the gate opening duration of the iCCD camera and point in time of the ignition spark. The breakdown is measured with a gate opening duration of $500 \mathrm{~ns}$. Then, the gate opening duration is increased to $10 \mu$ s until $100 \mu \mathrm{s}$ after the breakdown. After that, the gate duration is $100 \mu \mathrm{s}$ until the end of the ignition spark. The delay of the PTG trigger signal after each time step has the same duration as the gate opening duration in the previously measured time step. 20 images are created per time step. Therefore, several hundred sparks must be generated.

Finally, the gate opening is recorded with the oscilloscope. In this way, the image of the iCCD camera can be assigned to the point of time in the spark. In the postprocessing, the images are sorted by point in time of the spark based on their distance from the breakdown. 33].

The procedure is equivalent to earlier publications [30,

\subsection{Methodology}

This subsection is divided into four parts. In the first part, the energy calculation of the electrical measurement is explained. Then, the excitation of the vibrational levels and their effects on the spectra are explained. The third part shows the calculation method for determining the vibrational temperature. Finally, the measurement uncertainty of the temperature determination is discussed.

\subsubsection{Electrical measurement determination}

The calculation of the energy from the electrical measurement depends on the spark phase. Due to the short duration of the breakdown in which mainly the capacitance of $C_{\mathrm{SP} 2}$ discharges, the energy content of the breakdown $E_{B}$ is calculated by the following Eq. (1).

$E_{B}=\frac{1}{2} C_{S P 2} U_{B}^{2}$

With the voltage $U_{B}$ before the breakdown.

In the arc and the glow phase of the discharge, the discharge energy $E_{D}$ is calculated from the product of the voltage $U_{D}$ and the current $I_{D}$, which is integrated over the time $d t$. Due to the position of the voltage measurement upstream of the suppression resistor of the spark plug $R_{S P}$ the voltage drop across the spark plug resistor must be considered. This is done by subtracting the product of the suppression resistor and the measured current from the measured voltage. To get information about the electrical energy to the measured spectra, only the energy during the CCD open time is calculated $\left(t_{0}=\right.$ begin $C C D$ window, $t_{D}=$ end of CCD window). So, the calculation of the energies follows Eq. (2).

$E_{D}=\int_{t_{0}}^{t_{D}}\left(U_{D}-R_{S P} I_{D}\right) I_{D} d t$

\section{SN Applied Sciences}


A Matlab script is used to calculated the energy distribution of the different phases.

\subsubsection{Vibrational excitation}

The vibrational excitation of molecules is due to electron impact. In case of molecular nitrogen, the excitation to the second positive system (SPS) is described by Eq. (3).

$N_{2}(X)+e^{-} \rightarrow N_{2}\left(C_{3} \prod_{u^{\prime}} v=0,1,2, \ldots\right)+e^{-}$

Like the rotational excitation, the vibrational excitation within an electronically excited state has several energetic levels. Their energy can be at first approximately calculated from the harmonic oscillator using the Schrödinger's equation. However, due to the shape of the potential wall and the possibility of a transition with $\Delta v \neq \pm 1$, in practice the calculation is based on the anharmonic oscillator. The difficulty to describe the anharmonic oscillator analytically leads to the series development according to Dunham [34], which is shown in Eq. (4).

$$
\begin{aligned}
G(v)= & \omega_{e}\left(v+\frac{1}{2}\right)-\omega_{e} x_{e}\left(v+\frac{1}{2}\right)^{2} \\
& +\omega_{e} y_{e}\left(v+\frac{1}{2}\right)^{3}+\omega_{e} z_{e}\left(v+\frac{1}{2}\right)^{4}+\cdots
\end{aligned}
$$

With the constants $\omega_{e}, x_{e}, y_{e}$, and $z_{e}$ from the development of the Dunham series. The variable $v$ indicates the vibrational level and can take the values $v=0,1,2, \ldots$. Furthermore, this series development is coupled with the rotational equivalent by the Hund's coupling cases.

The result of these different transitions is shown in Fig. 3. On the left side a), the two electronic excited levels $N_{2}\left(C_{3} \prod_{u}\right.$ and $B_{3} \prod_{g}$ (both black), with different vibrational levels of the upper $\left(v^{\prime}\right)$ and the lower $\left(v^{\prime \prime}\right)$ (both blue) electronic excited states, and rotational levels $J$ ' and $J^{\prime \prime}$ (both red) are schematically shown. In the picture b), the result of these transition is shown as a spectrum in the wavelength range from 310 to $390 \mathrm{~nm}$. Several groupings of transitions are shown, according to the difference between the lower and upper energy levels $\Delta v$. Each of these groupings starts at its longest wavelength with the transition from the upper energy level $v^{\prime}=0$ to a lower energy level of $v^{\prime \prime}=0-\Delta v$. Towards the shorter wavelengths within these groupings, the energy level $v^{\prime}$ increases while $\Delta v$ remains constant. This is illustrated by the blue lines of the transitions $\Delta v=-1$. The rotational bands (red) lie between the individual vibrational lines. The energy contained in these vibrational excited levels is often referred as temperature and can be expressed in the unit kelvin. A calculation of the vibrational temperature can be achieved by using these vibrational transitions at the same $\Delta v$ or at different $\Delta v$ and the same upper level $v^{\prime}$.

\subsubsection{Vibrational temperature determination}

The comparison of simulated and experimentally determined spectra is a common method for determining oscillation temperature of non-equilibrium plasma [35-37]. The Matlab code SPARTAN 2.6 [38, 39], which uses the described relations described in the previous section, serves as the simulation tool. Both, the vibrational and the rotational temperature are varied in the simulations. In addition, the instrumental broadening function is transferred to the simulation. The simulated temperature range is from $300 \mathrm{~K}$ to $6050 \mathrm{~K}$ for rotational temperature and from $1950 \mathrm{~K}$ to $11,000 \mathrm{~K}$ for vibrational temperature. The step size between each simulation is $250 \mathrm{~K}$ and $50 \mathrm{~K}$ for the rotational and vibrational temperature, respectively. The electron temperature is set to $10,000 \mathrm{~K}$ in each simulation. Thus, the measured spectra are compared with about 4300 simulated spectra stored
Fig. 3 a Schematic illustration of the electronic (black), vibrational (blue) and rotational (red) energy levels of the SPS of $\mathrm{N}_{2}$. b Shows a spectrum resulting from different transitions in the SPS from (a). The $\Delta v$ shows the difference from the vibrational level of the higher electronic level to the vibrational state $v^{\prime}$ to vibrational level of the lower electronic level
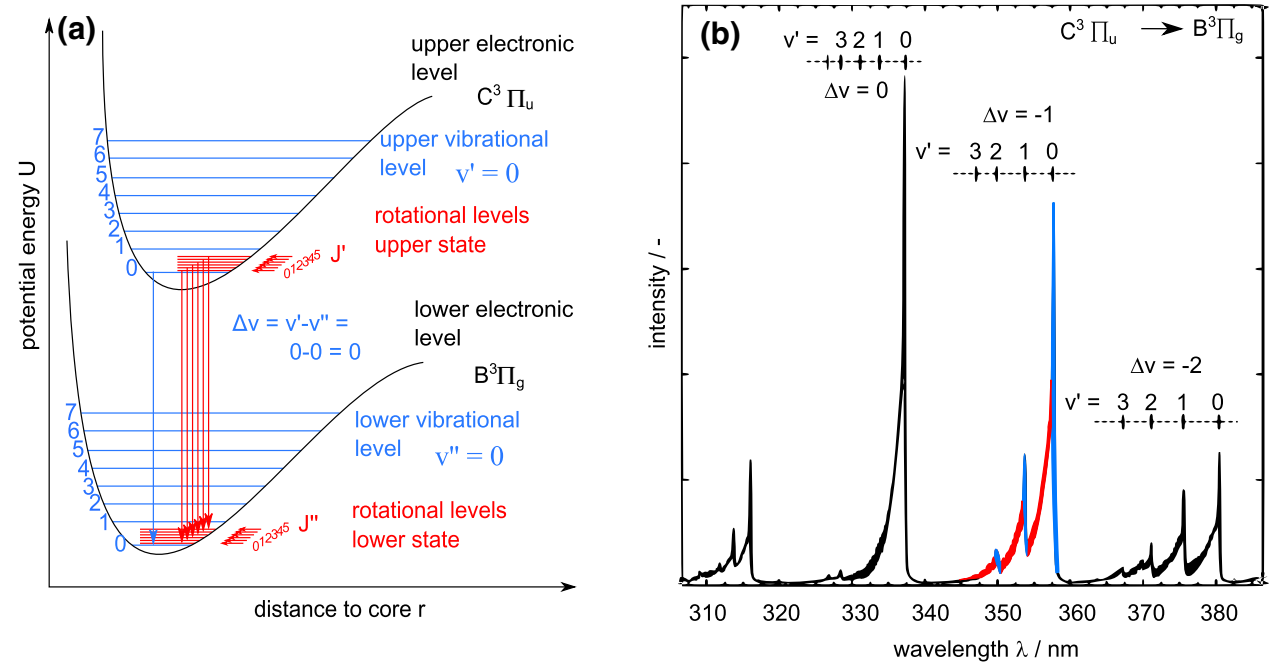

SN Applied Sciences A SPRINGER NATURE journa 
in a comparison database. The comparison is done by cross correlation in direction of the wavelength axis. The simulated spectrum with the largest cross correlation coefficient is selected and its temperature is taken as the vibrational temperature.

The observed spectra of the SPS is the following transition in $\mathrm{N}_{2} C^{3} \prod_{\mathrm{u}} \rightarrow B^{3} \prod_{\mathrm{g}}, \Delta v=-2$, within the wavelength range of $365 \mathrm{~nm}$ to $380.5 \mathrm{~nm}$. This wavelength range is frequently used in the literature [40-43]. In this wavelength range, the vibrational states are hardly superimposed by other species such as the first negative system (FNS), nickel from the cathode material or atomic oxygen. The following Fig. 4 shows some spectra with different vibrational temperatures. The rotational and electron temperature are fixed at $3000 \mathrm{~K}$ and $10,000 \mathrm{~K}$ in this figure. To compare the shape of the spectra, they are normalized to their maximum value. From the graph it can be seen, that with increasing vibration temperature the distinction between two temperature levels become more and more difficult. This influence on the calculation error of the vibrational temperature is discussed in the next section.

In order to calculate the spectra with the explained method, some assumptions have to be made, which are explained in the following.

First, SPARTAN uses a Maxwellian electron energy distribution function (EEDF) to calculate Doppler broadening, photoionization transitions, photodissociation transitions and Bremsstrahlung transitions. For vibrational temperature calculation only the effect of Doppler broadening $\Delta \lambda_{D}$ is considered, since it is included

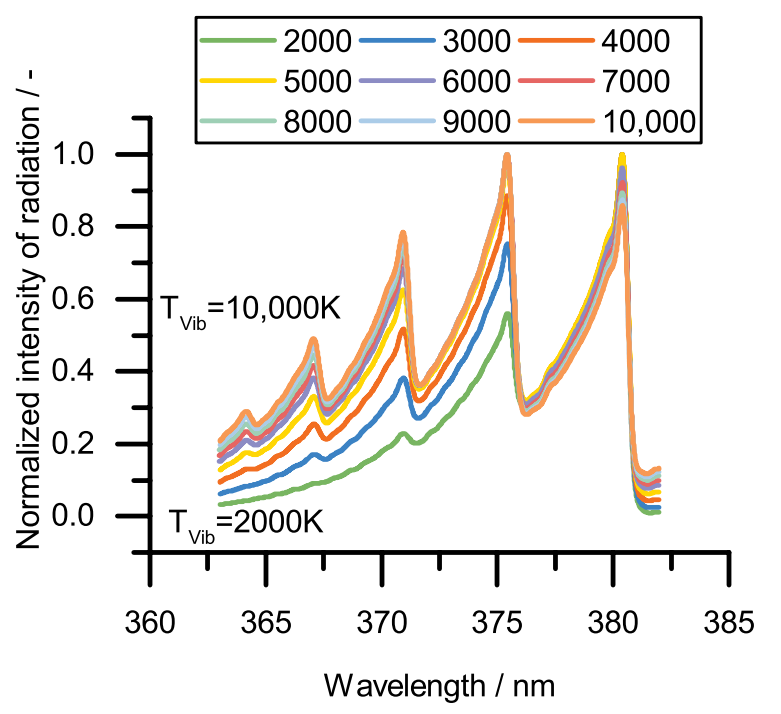

Fig. 4 Simulated spectra of $C^{3} \prod_{u} \rightarrow B^{3} \prod_{g}, \Delta v=-2$ at various vibrational temperatures between $2000 \mathrm{~K}$ and $10,000 \mathrm{~K}$ with an instrumental broadening function of $0.49 \mathrm{~nm}$ in the calculation of the temperature. For estimation of this effect Eq. (5) is used.

$\Delta \lambda_{D}=2 \sqrt{\ln (2)} \frac{\lambda_{0}}{c} \sqrt{\frac{2 k_{B} T_{g}}{m_{N_{2}}}}$

For the approximation we use the wavelength $\lambda_{0}=380 \mathrm{~nm}$ (which corresponds approximately to the transition $\Delta v=-2$ and $v^{\prime}=0$ ), the speed of light $c$, the Boltzmann constant $k_{B}$, the mass of molecular nitrogen $m_{\mathrm{N}_{2}}$ and the gas temperature $T_{g}=2300 \mathrm{~K}$, which was obtained from the rotational temperature of a previous work [44]. These values result in a Doppler broadening of $2.47 \mathrm{pm}$, which is negligible compared to the instrumental broadening of $490 \mathrm{pm}$.

SPARTAN assumes a Boltzmann equilibrium of the rotational levels to calculate the line intensity. Furthermore, a Boltzmann population of the vibrational levels is assumed. The most likely error in this assumption is the neglecting of overpopulated vibrational levels. Several studies [45-48] show, that the overpopulation of the vibrational levels becomes significant at vibrational quantum numbers of about three or higher. Considering the transitions of vibrational quantum numbers zero to two, as shown in Fig. 5, the influence of overpopulation is not expected to be dominant. An overpopulation, if it mainly affects the vibrational quantum numbers greater than or equal to one, would lead to a slight overestimation of the vibrational temperature.

The simulation does not include quenching effect of other species. By considering the deactivation constants of the vibrational levels from $v^{\prime}=0-3$ for different quenching partners shown in [49] (which show similar values for all vibrational levels for same quenching partners), we assume that the quenching effects act in the same way on all observed energy levels. Therefore, we are allowed to assume that quenching is negligible.

\subsubsection{Measurement uncertainties}

To determine the error in the computational process, four simulated spectra with different vibrational and rotational temperatures are used. The selected steps of $2050 \mathrm{~K}$, $2550 \mathrm{~K}, 5050 \mathrm{~K}$ and $9800 \mathrm{~K}$ are exemplary and result from the determined vibrational temperatures during the ignition spark, which are common in this investigation. The rotational temperatures of $300 \mathrm{~K}$ and $2800 \mathrm{~K}$ used are derived from breakdown, arc and glow discharge temperatures from previous observations [44]. These spectra are superimposed by various noises from 5 to $50 \%$. The noise is multiplied with the intensity of the signal, which is then normalized. They are then analyzed by the computational process. The maximum calculated errors are given in 


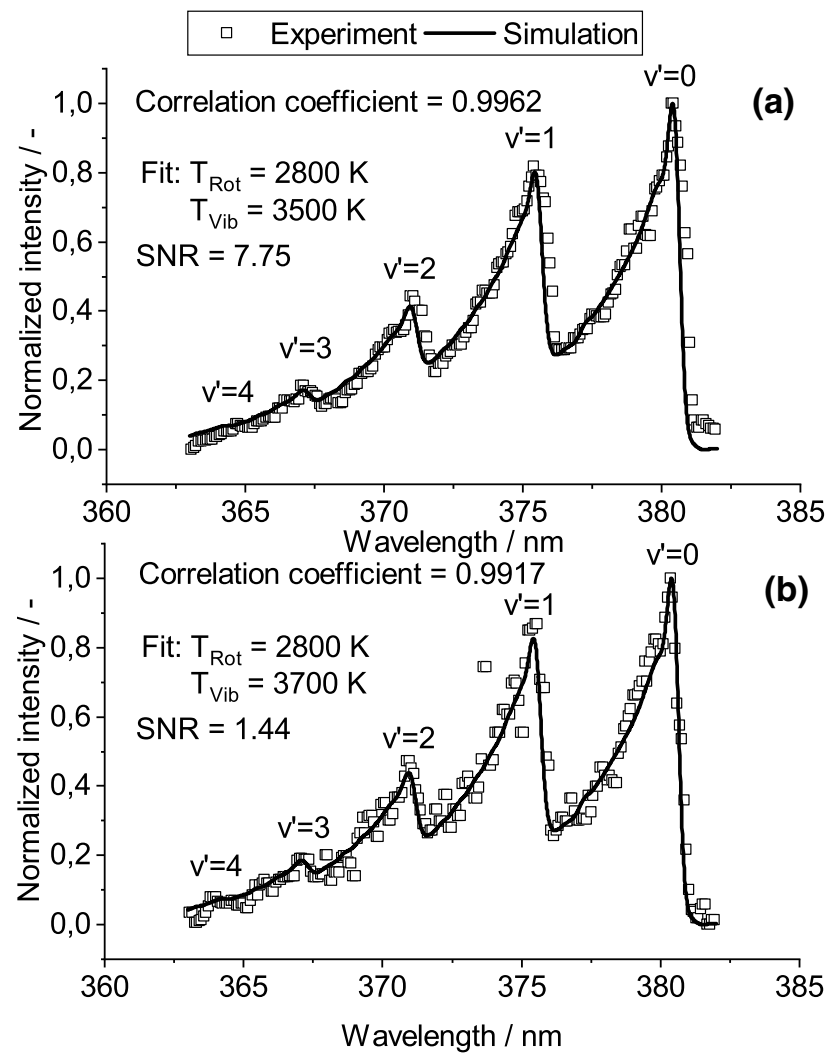

Fig. 5 Two spectra with different signal-to-noise ratios (SNR) and the corresponding fit. a Fit of a spectrum in the negative glow of a glow discharge with high signal-to-noise ratio of 7.75. $\mathbf{b}$ Fit of a spectrum in the positive column of a glow discharge with a low signal-to-noise ratio of 1.44. The given signal-to-noise ratio is calculated from the quotient of the signal intensity and the background noise

Table 1 Calculated maximum absolute and percentage error at different vibrational $\left(T_{\mathrm{Vib}}\right)$ and rotational temperatures $\left(\mathrm{T}_{\mathrm{Rot}}\right)$

\begin{tabular}{llll}
\hline $\mathrm{T}_{\text {Vib }}$ & $\mathrm{T}_{\text {Rot }}$ & Maximum error/K & $\begin{array}{l}\text { Maxi- } \\
\text { mum } \\
\text { error/\% }\end{array}$ \\
\hline 2050 & 300 & 250 & 12.2 \\
2550 & 2800 & 350 & 13.7 \\
5050 & 2800 & 550 & 10.9 \\
9800 & 2800 & 1650 & 16.8 \\
\hline
\end{tabular}

Table 1. Errors of this magnitude occur only in poor signalto-noise ratios. For medium and high signal-to-noise ratios with noise of up to $20 \%$, the error in determining the vibrational temperature is less than $7 \%$, which is in the order of magnitude of other investigations on laboratory plasma $[25,36,37,50]$, which is obviously not the same as plasma in the ignition spark. As an example for the temperature determination, the spectrum in the negative glow region a) and the positive column region b) is shown in Fig. 5 .
As the vibrational temperature increases, the maximum error $E R$ increases due to the smaller difference between the spectra.

Assuming an exponential behavior of the maximum error, it can be estimated by the following Eq. (6). For calculation, the three maximum errors at a rotational temperature of $2800 \mathrm{~K}$ are used.

$E R\left(T_{\text {Vib }}\right)=184.8 \times e^{\left(0.0002233 \times T_{\text {Vib }}\right)}$

The coefficient of determination $\mathrm{R}^{2}$ of this function is 0.999 . Therefore, it is a sufficiently good approximation to the maximum error.

\section{Results}

The following section contains an overview of the electrical and temperature measurements. First, the electrical results are evaluated. Then, the results of the vibrational temperature of the breakdown, the arc discharge and the glow discharge are each presented in a separate subsection.

All tests are performed with air at atmospheric pressure and a temperature of $23^{\circ} \mathrm{C}$.

\subsection{Electrical results}

The averaged results of the calculated supplied electric energy are shown in Table 2. The breakdown has an energy of approx. $0.1 \mathrm{~mJ}$ and does not change with the dwell time. In contrast to the breakdown energy and duration, the arc discharge energy and duration depend on the dwell time. The energy decreases from $3.8 \mathrm{~mJ}$ at $100 \%$ dwell time to $0.1 \mathrm{~mJ}$ at $25 \%$ dwell time. This reduction of arc discharge is also reflected in the duration, which decreases from 43.2 to $17 \mu$ s from the 100 to $75 \%$ dwell time. A further, but smaller reduction follows up to a duration of $2 \mu \mathrm{s}$ at a dwell time of $25 \%$. The glow discharge behaves similarly. A continuous decrease in the energy from 18.9 to $4.8 \mathrm{~mJ}$ with decreasing dwell time is observed. In contrast, a small increase in glow discharge duration of approx. $50 \mu \mathrm{s}$ is

Table 2 Calculated electrical energy

\begin{tabular}{llllll}
\hline $\begin{array}{l}\text { Dwell } \\
\text { time/\% }\end{array}$ & $\begin{array}{l}\text { Break- } \\
\text { down/ } \\
\mathrm{mJ}\end{array}$ & $\begin{array}{l}\text { Arc dis- } \\
\text { charge/ } \\
\mathrm{mJ}\end{array}$ & $\begin{array}{l}\text { Glow dis- } \\
\text { charge/ } \\
\mathrm{mJ}\end{array}$ & $\begin{array}{l}\text { Arc dura- } \\
\text { tion/ } \mu \mathrm{s}\end{array}$ & $\begin{array}{l}\text { Glow } \\
\text { dura- } \\
\text { tion/ } \\
\mu \mathrm{s}\end{array}$ \\
\hline 100 & 0.1 & 3.8 & 18.9 & 43.2 & 1013 \\
75 & 0.1 & 1.0 & 16.7 & 17.0 & 1069 \\
50 & 0.1 & 0.2 & 12.1 & 7.7 & 927 \\
25 & 0.1 & 0.1 & 4.8 & 2.0 & 572 \\
\hline
\end{tabular}


Fig. 6 Cumulative energy of the breakdown ('B', solid line), arc discharge ('A', dotted line) and glow discharge ('G', dashed line) at an ignition coil dwell time of $100 \%$ (green), $75 \%$ (blue), $50 \%$ (orange) and $25 \%$ (yellow)

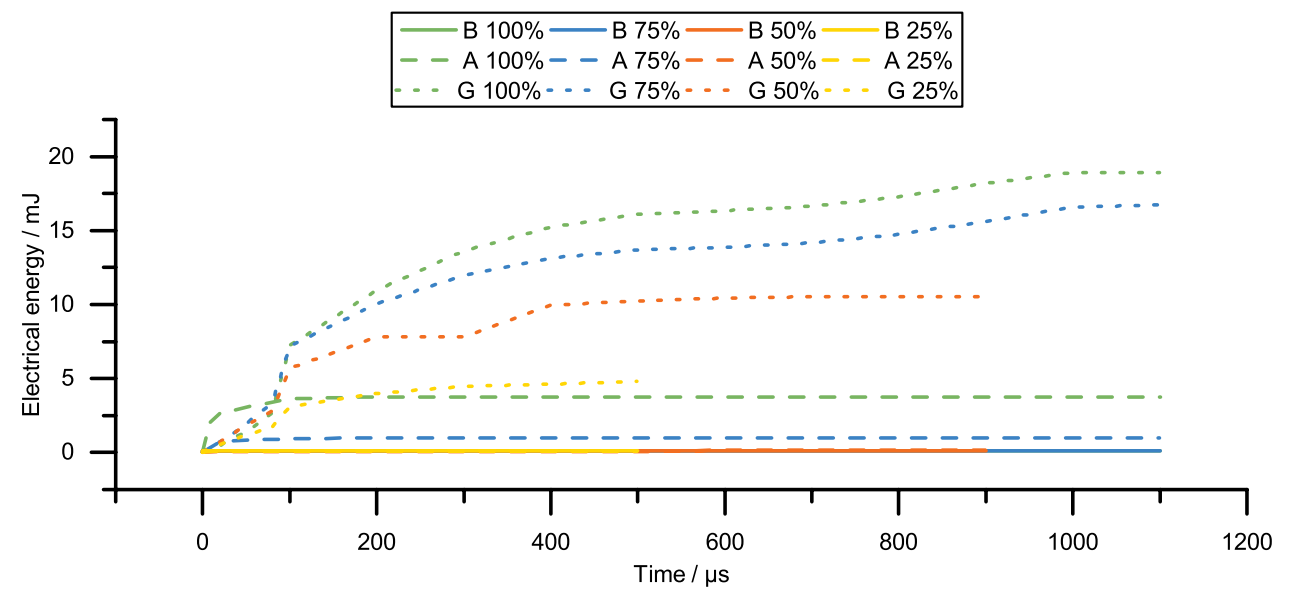

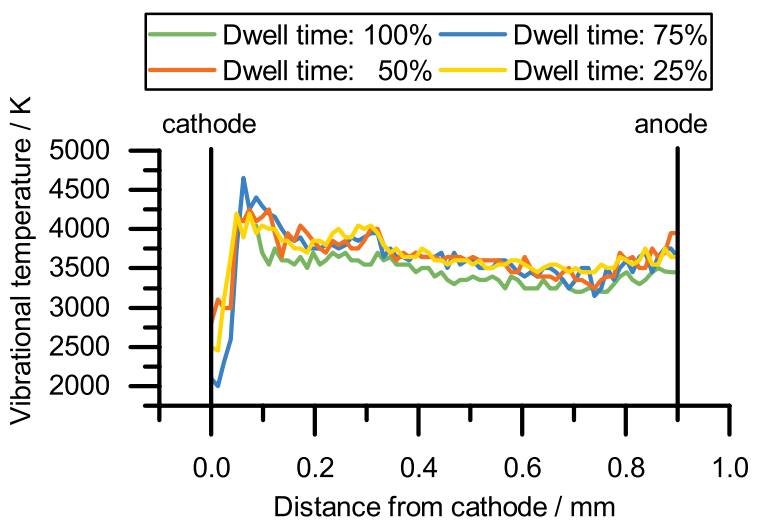

Fig. 7 Vibrational temperature during the breakdown depending on the distance to the cathode

observed by reducing the dwell time from 100 to $75 \%$. This is most likely due to the reduction of the arc discharge duration.

In addition to the averaged results, the cumulative electrical energy as a function of time and the discharge mechanism is shown in Fig. 6 . The arc discharge is dominant only in the first about $40 \mu$ s and at a dwell time of $100 \%$. In this time interval, the current is high, resulting in high current densities and thus an increased possibility for arc discharges. If the dwell time is reduced, the current at the beginning of the inductive discharge decreases. This leads to less arcing and a lower energy input into the gas.

\subsection{Vibrational temperature in the breakdown}

Figure 7 shows the vibrational temperature of the breakdown above the discharge gap with different dwell times. For all dwell times, the trends are similar, considering the error of $\pm 380 \mathrm{~K}$ to $\pm 460 \mathrm{~K}$ (depending on the measured temperature). From a temperature of about $2500 \mathrm{~K}$ $\pm 320 \mathrm{~K}$ at the cathode, an increase to $4250 \mathrm{~K} \pm 480 \mathrm{~K}$ can be

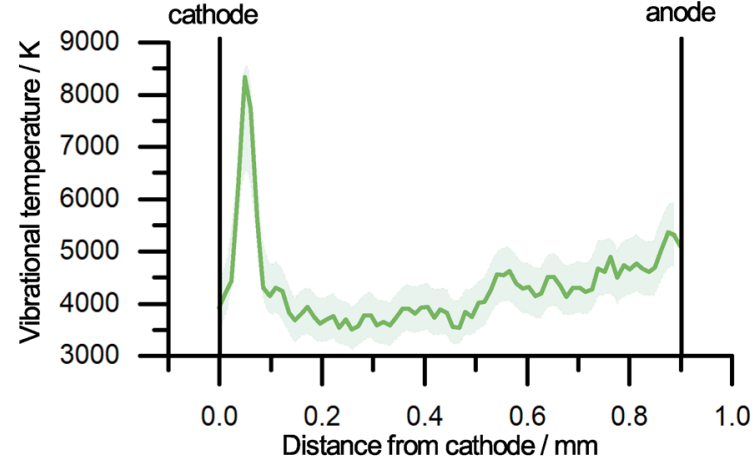

Fig. 8 Vibrational temperature during the arc phase in dependence from the distance to the cathode

observed at a distance of $0.06 \mathrm{~mm}$ from the cathode. This can be explained by the acceleration of the electrons from the cathode, which leads to this increase [42]. At the dwell time of $100 \%$, the signal-to-noise ratio did not allow evaluation of the first $0.07 \mu \mathrm{m}$. After this peak, a slight decrease of vibrational temperature to about $3300 \mathrm{~K}$ is measured up to a distance of $0.75 \mathrm{~mm}$ from the cathode. Following this minimum, an increase in the vibrational temperature is calculated. This is most probably due to a decrease of the signal-to-noise ratio, which could lead to a higher calculated vibrational temperature.

\subsection{Vibrational temperature in the arc phase}

As discussed in Sect. 3.1, a relatively stable arc only occurs at a dwell time of $100 \%$. For this reason, Fig. 8 shows only the $100 \%$ dwell time curve above the distance from the cathode. The envelope curve shows the maximum error calculated from Eq. (6). Similar to the breakdown, the vibrational temperature increases strongly up to a distance of approximately $0.05 \mathrm{~mm}$ from the cathode. The maximum vibrational temperature at this distance is $8350 \mathrm{~K}$ 
$\pm 1200 \mathrm{~K}$. After that, the vibrational temperature decreases to values of $3750 \mathrm{~K} \pm 400 \mathrm{~K}$. At a distance of approximately $0.5 \mathrm{~mm}$ from the cathode, a slight increase in the vibrational temperature to about $4350 \mathrm{~K}$ in is measured. Due to the measuring principle, arc and glow discharges may both occur during the accumulation time of the CCD. Due to the strong intensity of radiation of the negative glow of glow discharges, the range between 0.1 and $0.5 \mathrm{~mm}$ is affected by this overlap. By neglecting the small cathode and anode drop area of a few mean free path lengths (one mean tree path length in air under standard conditions is between 65 and $68 \mathrm{~nm}$ [51-53]), the arc discharge consists only of a positive column. In this area the intensity of radiation is mainly caused by electron impacts. Due to the overlap between the negative glow of the glow and the positive column of the arc discharge, an average temperature is determined from both. The hotter area of the positive column (from $0.5 \mathrm{~mm}$ to the end) suggests that the temperature in the overlap area is underestimated.

\subsection{Vibrational temperature in the glow phase}

Compared to arc discharges, the plasma structure of glow discharges varies much more across the discharge gap [54]. Figure 9 shows the vibrational temperature (solid lines) and the intensity of radiation (dashed lines) at $200 \mu$ s (green) and $400 \mu s$ (blue) across the discharge gap at a dwell time of $50 \%$. As with the breakdown and the arc discharge, the vibrational temperature of the glow discharge has its maximum of $6500 \mathrm{~K} \pm 830 \mathrm{~K}$ at a distance of $0.05 \mathrm{~mm}$ from the cathode. Between 0.1 and $0.45 \mathrm{~mm}$ the negative glow results in a high intensity of radiation and a vibrational temperature of $3500 \mathrm{~K} \pm 400 \mathrm{~K}$. With decreasing intensity from a distance of $0.45 \mathrm{~mm}$ from the cathode, the vibrational temperature increases to $4350 \mathrm{~K}$ $\pm 490 \mathrm{~K}$. After that, only a weak radiation is measured. the vibrational temperature in this area is constant at a value of $3900 \mathrm{~K} \pm 440 \mathrm{~K}$. With decreasing intensity of radiation starting at $0.8 \mathrm{~mm}$, the vibrational temperature increases slightly, which is most probably again due to the lower signal-to-noise ratio.

To determine the influence of the dwell time on the vibrational temperature, the values of the negative glow (from 0.1 to $0.4 \mathrm{~mm}$ ), and the values of the positive column (from 0.5 to $0.8 \mathrm{~mm}$ ) are each averaged. The dependence of the vibrational temperature in the negative glow and the positive column from the dwell time is shown in Figs. 10 and 11. The different colored lines are indicating different time intervals during the discharge. The vibrational temperature in the negative glow is independent of the dwell time at $3500 \mathrm{~K} \pm 400 \mathrm{~K}$. Only the $\mathrm{t}=600 \mu \mathrm{s}$ and $\mathrm{t}=900 \mu \mathrm{s}$ intervals show an effect at $25 \%$ and $50 \%$ dwell time and increase to a vibrational temperature of $3800 \mathrm{~K} \pm 430 \mathrm{~K}$. This is due to the discharge end in these time intervals for the two dwell times mentioned (showed in Table 2), which causes the intensity to drop sharply. As described above, the signal-to-noise ratio decreases and
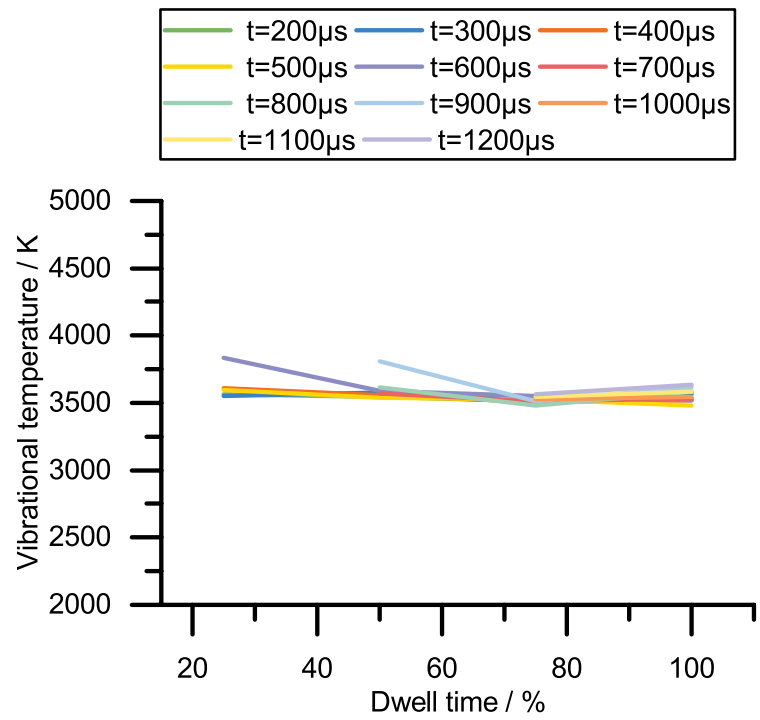

Fig. 10 Vibrational temperatures of different time intervals in the negative glow depending on the dwell time of the ignition coil
Fig. 9 Vibrational temperature (solid lines) and intensity (dashed lines) at $200 \mu$ s (green) and $400 \mu$ s (blue) after breakdown depending the distance to the cathode

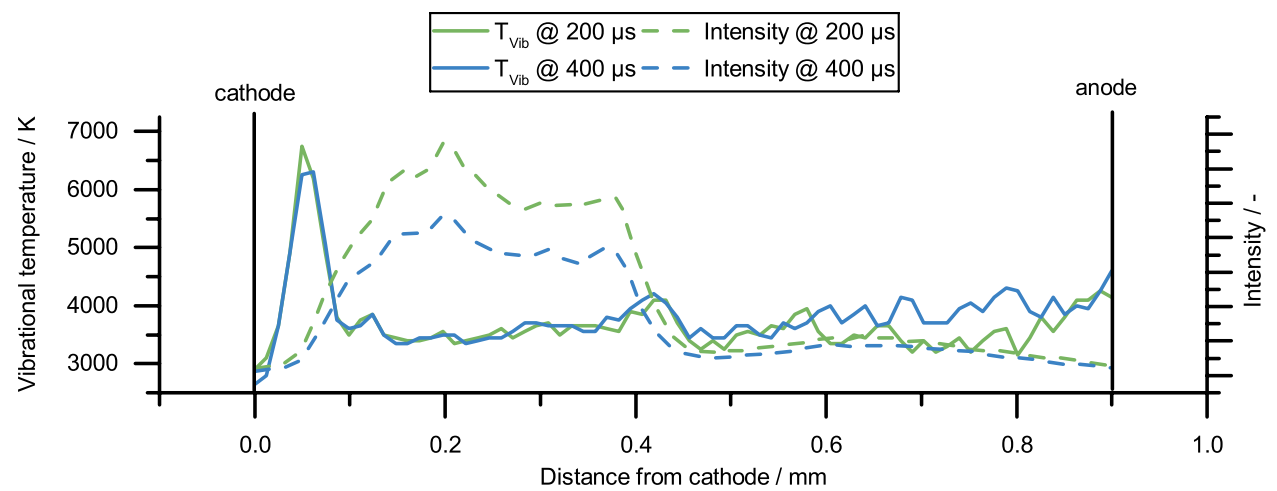

SN Applied Sciences A SPRINGER NATURE journal 

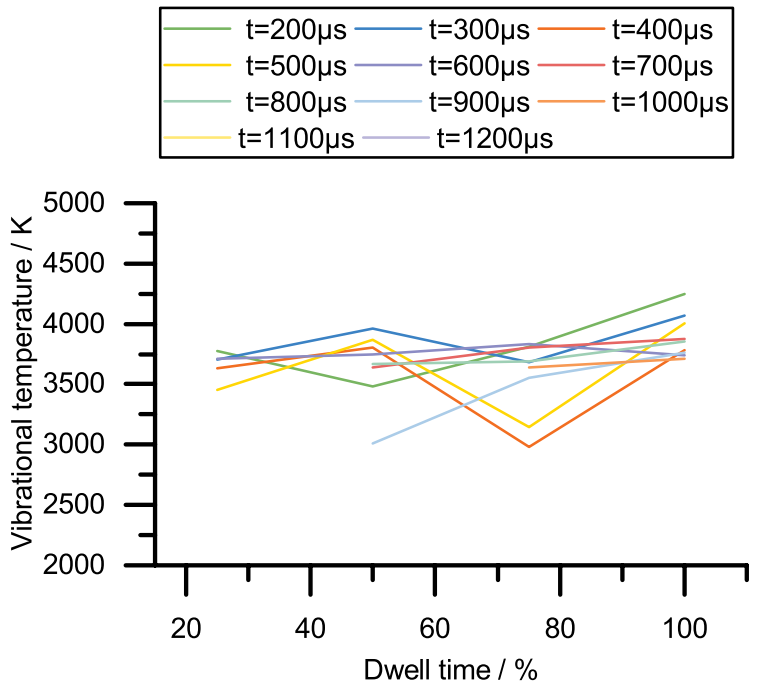

Fig. 11 Vibrational temperatures of different time intervals in the positive column depending on the dwell time of the ignition coil

the calculated vibrational temperature may increase as a result. This relativizes the higher vibrational temperature.

In the positive column the significantly lower intensity leads to higher variations of the calculated vibrational temperature. The mean value of approximately $3900 \mathrm{~K}$ seems to be independent from the dwell time, considering the uncertainty of $\pm 440 \mathrm{~K}$.

\section{Discussion}

No influence of the dwell time on the vibrational temperature and the electrical energy of the breakdown was measured. As mentioned in Sect. 2.2.1, the energy of this discharge is supplied mainly by the capacitor $\mathrm{C}_{\mathrm{SP} 2}$ of the spark plug. In addition, the breakdown voltage can be estimated by Paschen's law, which is independent from the dwell time and is a function of the gas, electrode gap and pressure. The above mentioned parameters have been fixed in all tests. Therefore, no change in the static breakdown voltage according to Paschen's law is to be expected. Also influence of the dwell time on inhomogeneities of the electric field or over-voltage effects due to the rise time of capacitor charging are negligible. Therefore, there is no influence of the dwell time on Eq. (1), which makes the supplied energy independent of the dwell time. In the breakdown the measured constant vibrational temperature confirms this assumption.

Only at $100 \%$ dwell time the arc discharge is the dominant source of radiation in the first $40 \mu \mathrm{s}$ of the discharge. Therefore, the spectrum of the arc discharge is only slightly distorted by a small occurrence of the glow discharge during the accumulation time of the CCD. As the dwell time

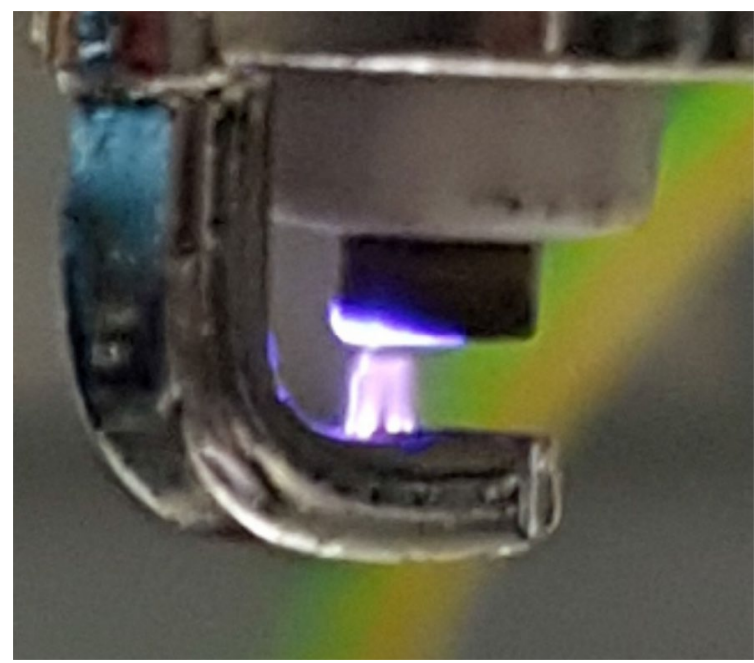

Fig. 12 Photograph of a typical ignition spark with an exposure time of $1 / 25 \mathrm{~s}$. The picture shows the distribution of the discharge over the $2.5 \mathrm{~mm}$ wide cathode surface. At no time, the discharge covers the entire cathode

decreases, the current at the beginning of the inductive discharge is reduced. This is in contrast to the high currents needed for arc discharges. Below $75 \%$ dwell time the current at the beginning of the inductive discharge is lower than $100 \mathrm{~mA}$, which turned out to be a limit for arcing in earlier researches [44].

The vibrational temperature of the negative glow and the positive column of the glow discharge is independent from the dwell time. Only the intensity, and therefore the number of excited molecules decreases. A spark plug with a cathode diameter of $2.5 \mathrm{~mm}$ is used. Photographs of the entire ignition spark, as shown as an example in Fig. 12, showed, that the discharge at no time covers more than half of the cathode. The glow discharge thus has enough space to propagate, since it strives for a constant current density. Consequently, an increase in current leads to an increase in the discharge diameter and not to an increase in current density, which means that the vibrational temperature remains constant [55].

\section{Conclusion}

We have developed a method for measuring and calculating the vibrational temperature of an ignition spark plasma in spatial and temporal resolution. First tests by variation of an ignition system control parameter, the dwell time, and its effect on the vibrational temperature in different phases of the ignition spark were performed. In addition, we are able to calculate the energy distribution to the breakdown, arc, and glow phase of the ignition spark with electrical measurements. These electrical 
measurement results are assigned to the spectroscopic measured values, which allows the evaluation of the influence of different parameters of the ignition system on the ignition spark.

The vibrational temperature of the breakdown was in the range of $3300 \mathrm{~K} \pm 360 \mathrm{~K}$ and is independent of the dwell time due to its capacitive discharge behavior.

Shortening the dwell time resulted in less arcing due to the lower initial current in the inductive part of the discharge. Therefore, a stable arc discharge of sufficient length could only be observed at the maximum dwell time of the ignition coil. The vibrational temperature of the observed arc discharge is in the range of $3750 \mathrm{~K} \pm 430 \mathrm{~K}$ to $4350 \mathrm{~K} \pm 490 \mathrm{~K}$.

The glow discharge is mainly divided in the two areas of negative glow and positive column. By changing the dwell time, no influence of the vibrational temperature in the negative glow and the positive column is observed. This is most probably due to the fact, that the glow discharge has a constant current density and sufficient space to propagate. The vibrational temperature ranges from $3500 \mathrm{~K} \pm 400 \mathrm{~K}$ to $3900 \mathrm{~K} \pm 440 \mathrm{~K}$ in the negative glow and the positive column, respectively.

The next steps in planned research activities will be the calculation of the electron temperature and the electron density of the ignition phases. In addition, further tests will be performed under elevated pressure and temperature conditions in a heated pressure chamber designed for this purpose.

Acknowledgements Open Access funding provided by Projekt DEAL. Financial support from the 'Ministerium fãijr Wissenschaft, Forschung und Kunst Baden-WÃijrttemberg' (Project 'Profilregion MobilitÃd'tssysteme Karlsruhe', Project No. AZ::32-7544-0/76/6).

\section{Compliance with ethical standards}

Conflict of interest The authors declare that they have no conflict of interest.

Open Access This article is licensed under a Creative Commons Attribution 4.0 International License, which permits use, sharing, adaptation, distribution and reproduction in any medium or format, as long as you give appropriate credit to the original author(s) and the source, provide a link to the Creative Commons licence, and indicate if changes were made. The images or other third party material in this article are included in the article's Creative Commons licence, unless indicated otherwise in a credit line to the material. If material is not included in the article's Creative Commons licence and your intended use is not permitted by statutory regulation or exceeds the permitted use, you will need to obtain permission directly from the copyright holder. To view a copy of this licence, visit http://creativecommons .org/licenses/by/4.0/.

\section{References}

1. European Commission. 2030 climate \& energy package (2018). https://ec.europa.eu/clima/policies/strategies/2030_en

2. European Commission. A Clean Planet for all: A European strategic long-term vision for a prosperous, modern, competitive and climate neutral economy (2018). https://eur-lex.europa.eu/legal -content/EN/TXT/?uri=CELEX:52018DC0773

3. Kramer U, Ortloff F, Stollenwerk S (2018) Defossilisierung des Transportsektors: Optionen und Voraussetzungen in Deutschland. Forschungsvereinigung Verbrennungskraftmaschinen (FVV) e.V. (FVV,). https://books.google.de/books $? \mathrm{id}=7$ NLyxQEACAAJ

4. Schmidt P, Zittel W, Weindorf W, Raksha T Renewables in Transport 2050: Empowering a sustainable mobility future with zero emission fuels from renewable electricity-Europe and Germany: Kraftstoffstudie II

5. Koch T, Sauer, J, Toedter O, Hirth T (2019) reFuels - Notwendigkeit und Herausforderungen Automobiltechnische Zeitschrift 24(Sonderprojekt ATZ/MT), 28

6. Weber P, Toedter O, Buchgeister J, Koch T (2019) Ökobilanzierung - Kontroversen vorprogrammiert? Sonderprojekte ATZ/ MTZ 24(S2):12. https://doi.org/10.1007/s41491-019-0042-y

7. Hurtig O (2014) Techno-ökonomischer Vergleich des Einsatzes von Strom, SNG und FT-Diesel aus Waldrestholz im Pkw-Bereich. https://doi.org/10.5445/KSP/1000037701

8. Potteau S, Lutz P, Leroux S, Moroz S, Tomas E (2007) Cooled EGR for a Turbo SI Engine to Reduce Knocking and Fuel Consumption in SAE Technical Paper Series (SAE International, Warrandale,). SAE Technical Paper Series. https://doi. org/10.4271/2007-01-3978

9. Alger T, Mangold B (2009) Dedicated EGR: a new concept in high efficiency engines SAE. Int J Eng 2(1):620

10. Akif Ceviz M, Sen AK, Volkan Küleri AK, Öner I (2012) Engine performance, exhaust emissions, and cyclic variations in a lean-burn SI engine fueled by gasoline-hydrogen blends. Appl Therm Eng 36:314. https://doi.org/10.1016/j.appltherma leng.2011.10.039

11. Dale JD, Checkel MD, Smy PR (1997) Application of high energy ignition systems to engines. Prog Energy Comb Sci 23(5):379. https://doi.org/10.1016/S0360-1285(97)00011-7

12. Chen W, Madison D, Dice P, Naber J, Chen B, Miers S, Czekala M, Glugla C, Qu Q, Huberts g (2013) Impact of ignition energy phasing and spark gap on combustion in a homogenous direct injection gasoline SI engine near the EGR limit in SAE Technical Paper Series (SAE International, Warrendale,). SAE Technical Paper Series. https://doi.org/10.4271/2013-01-1630

13. Zhou M, Li G, Liang J, Ding H, Zhang Z (2019) Effect of ignition energy on the uncertainty in the determination of laminar flame speed using outwardly propagating spherical flames. Proc Comb Inst 37(2):1615. https://doi.org/10.1016/j.proci .2018.07.084

14. Young MB (1981) Cyclic Dispersion in the Homogeneous-Charge Spark-Ignition Engine-A Literature Survey in SAE Technical Paper Series (SAE International, Warrendale,). SAE Technical Paper Series. https://doi.org/10.4271/810020

15. Ozdor N, Dulger M, Sher E (1994) Cyclic Variability in Spark Ignition Engines A Literature Survey in SAE Technical Paper Series (SAE International, Warrendale,). SAE Technical Paper Series. https://doi.org/10.4271/940987

16. Pischinger S (1989) Effects of Spark Plug Design Parameters on Ignition and Flame Development in an Si-engine. Dissertation, Massachusetts Institute of Technology, Cambridge. https:// books.google.de/books?id=ziTzNwAACAAJ 
17. Toulson E, Schock HJ, Attard WP (2010) A Review of Pre-Chamber Initiated Jet Ignition Combustion Systems in SAE Technical Paper Series (SAE International, Warrendale,). SAE Technical Paper Series. https://doi.org/10.4271/2010-01-2263

18. Szwaja S, Jamrozik A, Tutak W (2013) A two-stage combustion system for burning lean gasoline mixtures in a stationary spark ignited engine. Appl Energy 105:271. https://doi.org/10.1016/j. apenergy.2012.12.080

19. Janas P, Niessner W (2018) Towards a thermally robust automotive pre-chamber spark plug for turbocharged direct injection gasoline engines. https://doi.org/10.5445/IR/1000088323

20. Maly R, Albrecht H, Bloss WH, Herden W, Saggau B, Wagner E (1977) Neue Ergebnisse über die Entflammung durch den elektrischen Funken 4th Satusseminar Kraftfahrzeug- und Straßenverkehrstechnik

21. Maly R, Herden W, Saggau B, Wagner E, Vogel M, Bauer G, Bloss WH (1978) Die drei Phasen einer elektrischen Zündung und ihre Auswirkungen auf die Entflammungseinleitung 5th Statusseminar Kraftfahrzeuge und Straßenverkehr

22. Maly R, Vogel M (1979) Initiation and propagation of flame fronts in lean $\mathrm{CH} 4$-air mixtures by the three modes of the ignition spark Symposium (International) on Combustion 17(1), 821. https://doi.org/10.1016/S0082-0784(79)80079-X

23. Maly R (1984) Spark ignition: its physics and effect on the internal combustion engine in fuel economy. In: Hilliard JC, Springer GS (eds) Road vehicles powered by spark ignition engines. Springer, Boston, pp 91-148. https://doi. org/10.1007/978-1-4899-2277-9_3

24. Oliveira C, Reis JL, Souza-Corrêa JA, Dal Pino A, Amorim J (2012) Optical and electrical diagnostics of a spark-plug discharge in air. J Phys D Appl Phys 45(25):255201. https://doi. org/10.1088/0022-3727/45/25/255201

25. Hnatiuc B, Astanei D, Pellerin S, Cerqueira N, Hnatiuc M (2014) Diagnostic of plasma produced by a spark plug at atmospheric pressure: reduced electric field and vibrational temperature contributions to. Plasma Phys 54(8):712. https://doi.org/10.1002/ ctpp.201300059

26. Huang S, Li T, Zhang Z, Ma P (2019) Rotational and vibrational temperatures in the spark plasma by various discharge energies and strategies. Appl Energy 251:113358. https://doi. org/10.1016/j.apenergy.2019.113358

27. Frei H, Pimentel GC (1983) Selective vibrational excitation of the ethylene-fluorine reaction in a nitrogen matrix I. J Chem Phys 78(6):3698. https://doi.org/10.1063/1.445144

28. Thomas A, George J, Shalabney A, Dryzhakov M, Varma SJ, Moran J, Chervy T, Zhong X, Devaux E, Genet C, Hutchison JA, Ebbesen TW (2016) Ground-State Chemical Reactivity under Vibrational Coupling to the Vacuum Electromagnetic Field Angewandte Chemie (International ed. in English) 55(38):11462. https://doi.org/10.1002/anie.201605504

29. Rogowski W (1936) Über Durchschlag und Gasentladung. Zeitschrift fr Physik 100(1-2):1. https://doi.org/10.1007/BF013 37744

30. Michler T, Kim W, Toedter O, Koch T, Bae C (2018) Influence of the electrical parameters of the ignition system on the phases of spark ignition in ignition systems for gasoline engines. In: Günther M (ed) 4th International conference, December 6-7, 2018, Berlin, Germany. expert Verlag, Tübingen, pp 222-238

31. Rager J (2006) Funkenerosion an Zündkerzenelektroden, Saarbrücker Reihe Materialwissenschaft und Werkstofftechnik, vol. Bd. 5 (Shaker, Aachen,)

32. Bauer H, Gollin W (2002) Zündung im Ottomotor, 1st edn. Gelbe Reihe: Fachwissen Kfz-Technik: Motorsteuerung für Ottomotoren (Robert Bosch GmbH, Stuttgart, Sep.)

33. Kim W, Bae C, Michler T, Toedter O, Koch T (2018) Spatio-temporally resolved emission spectroscopy of inductive spark ignition in atmospheric air condition in ignition systems for gasoline engines. In: Günther M (ed) 4th International conference, December 6-7, 2018, Berlin, Germany, vol. 2018 (expert Verlag, Tübingen), vol 2018, pp 209-221. https://doi.org/10.5445/ IR/1000088260

34. Dunham JL (1932) The energy levels of a rotating vibrator. Phys Rev 41(6):721. https://doi.org/10.1103/PhysRev.41.721

35. Laux CO, Spence TG, Kruger CH, Zare RN (2003) Optical diagnostics of atmospheric pressure air plasmas. Plasma Sources Sci Technol 12(2):125. https://doi.org/10.1088/0963-0252/12/2/301

36. Staack D, Farouk B, Gutsol AF, Fridman AA (2006) Spectroscopic studies and rotational and vibrational temperature measurements of atmospheric pressure normal glow plasma discharges in air. Plasma Sources Sci Technol 15(4):818. https:// doi.org/10.1088/0963-0252/15/4/027

37. Machala $Z$, Janda $M$, Hensel $K$, Jedlovský I, Leštinská L, Foltin V, Martišovitš V, Morvová M (2007) Emission spectroscopy of atmospheric pressure plasmas for bio-medical and environmental applications. J Mol Spectrosc 243(2):194. https://doi. org/10.1016/j.jms.2007.03.001

38. Lino da Silva M (2007) An adaptive line-by-line-statistical model for fast and accurate spectral simulations in low-pressure plasmas. J Quant Spectrosc Radiat Transf 108(1):106

39. Lino da Silva M (2011) A contribution for the simulation of VUV-IR radiation transfer in CO2-N2 entry flows using a lineby-line model in radiation of high temperature gases in atmospheric entry, vol 689

40. Blois D, Supiot P, Barj M, Chapput A, Foissac C, Dessaux O, Goudmand P (1998) The microwave source \textquotesingles influence on the vibrational energy carried by in a nitrogen afterglow. J Phys D Appl Phys 31(19):2521. https://doi. org/10.1088/0022-3727/31/19/025

41. Iza F, Hopwood JA (2004) Rotational, vibrational, and excitation temperatures of a microwave-frequency microplasma. IEEE Trans Plasma Sci 32(2):498. https://doi.org/10.1109/ TPS.2004.826145

42. Jiang W, Tang J, Wang Y, Zhao W, Duan Y (2014) Characterization of argon direct-current glow discharge with a longitudinal electric field applied at ambient air. Sci Rep 4:6323. https ://doi.org/10.1038/srep06323

43. Khan FU, Rehman NU, Naseer S, Naz MY, Khattak NAD, Zakaullah M (2011) Effect of excitation and vibrational temperature on the dissociation of nitrogen molecules in Ar-N 2 mixture RF discharge. Spectrosc Lett 44(3):194. https://doi. org/10.1080/00387010.2010.497527

44. Michler T, Toedter O, Koch T (2020) Measurement of temporal and spatial resolved rotational temperature in ignition sparks at atmospheric pressure. Automot Engine Technol 36:314. https://doi.org/10.1007/s41104-020-00059-w

45. Campbell DH, Muntz EP (1980) Non-Boltzmann, non-Treanor vibrational level populations of electrical discharge excited nitrogen. J Chem Phys 72(3):1487. https://doi. org/10.1063/1.439374

46. Jolly J, Touzeau M, Ricard A (1981) Determination of nonBoltzmann vibrational level populations of excited nitrogen using the Penning ionisation technique. J Phys B Atomic Mol Phys 14(3):473. https://doi.org/10.1088/0022-3700/14/3/024

47. Blackwell HE, Scott CD, Arepalli S (1998) Measured shocklayer vibrational populations and temperatures in arcjet nitrogen flow. J Thermophys Heat Transf 12(4):465. https:// doi.org/10.2514/2.6380

48. Rehman NU, Khan FU, Naveed MA, Zakaullah M (2008) Determination of excitation temperature and vibrational temperature of the N2(C $\left.3 \Pi u, v^{\prime}\right)$ state in Ne-N2RF discharges. Plasma Sources Sci Technol 17(2):025005. https://doi. org/10.1088/0963-0252/17/2/025005 
49. Pancheshnyi SV, Starikovskaia SM, Starikovskii A (2000) Collisional deactivation of $\mathrm{N} 2(\mathrm{C}, \mathrm{v}=0,1,2,3)$ states by $\mathrm{N} 2, \mathrm{O} 2$, $\mathrm{H} 2$ and $\mathrm{H} 2 \mathrm{O}$ molecules. Chem Phys 262(2-3):349. https://doi. org/10.1016/S0301-0104(00)00338-4

50. Pawelec E, Simek M, Nassar H, Czernichowski A, Musioł K, Dittrichova L (1996) Temperature measurements in nonequilibrium "ferroelectric". Plasma Acta Phys Pol A 89(4):503. https://doi.org/10.12693/APhysPolA.89.503

51. Jennings $S(1988)$ The mean free path in air. J Aerosol Sci 19(2):159. https://doi.org/10.1016/0021-8502(88)90219-4

52. Hinds WC (2012) Aerosol technology: properties, behavior, and measurement of airborne particles, 2 nd edn. Wiley-Interscience, New York

53. Zhao X, Wang S, Yin X, Yu J, Ding B (2016) Slip-effect functional air filter for efficient purification of PM2.5. Sci Rep 6:35472. https://doi.org/10.1038/srep35472
54. Bazeljan EM, Rajzer JP (1998) Spark discharge. CRC Press, Boca Raton

55. Farouk T, Farouk B, Staack D, Gutsol A, Fridman A (2006) Simulation of dc atmospheric pressure argon micro glowdischarge. Plasma Sources Sci Technol 15(4):676. https://doi. org/10.1088/0963-0252/15/4/012

Publisher's Note Springer Nature remains neutral with regard to jurisdictional claims in published maps and institutional affiliations. 